\title{
A concepção de ética no utilitarismo de John Stuart Mill
}

Maria Cristina Longo Cardoso Dias

UFRN 

Para que se entenda a ética no utilitarismo de John Stuart Mill é necessário compreender o modelo de indivíduo que se pode depreender a partir dos escritos do autor, pois, em última instância, pode-se afirmar que o que existe para o autor, para análise política e moral, é o indivíduo, sendo a sociedade uma composição desses agentes, embora o autor reconheça que para formação do caráter (etologia, em suas palavras) destes mesmos indivíduos seja fundamental a existência de arranjos institucionais sociais, educacionais (Mill, 2000, p. 196), que propiciem a convergência dos interesses individuais com os coletivos. Abaixo cita-se uma passagem na qual resta clara sua noção de sociedade como soma dos indivíduos:

Mas não é de modo nenhum, uma condição indispensável para a aceitação do modelo utilitarista, pois esse modelo não é a maior soma da felicidade do próprio agente, mas a maior soma de felicidade conjunta (Mill, 2000, p. 196).

O modelo de indivíduo de Mill, no que diz respeito à moral², é constituído por um modelo dinâmico, pois uma das características fundamentais da natureza deste indivíduo é a capacidade de se transformar qualitativamente ao longo do tempo. Note-se que esta capacidade de se modificar qualitativamente ao longo do tempo decorre da possibilidade do indivíduo experimentar prazeres de qualidades distintas. Além dessa capacidade, ressalta-se que o indivíduo apresenta, em sua natureza, faculdades elevadas de que derivam prazeres qualitativamente superiores, verdadeiramente humanos, tais como o prazer de ler um livro ou o prazer de ouvir uma boa música. Ademais, os indivíduos de Mill possuem a

1 Afirmar que o modelo utilitarista constitui a soma da felicidade conjunta dos indivíduos significa descrever que a sociedade é composta de indivíduos e sua soma constitui a sociedade, bem como a soma de suas felicidades constitui a felicidade geral da comunidade, prescrição feita pelo princípio de utilidade.

2 Sobre a noção de natureza humana do indivíduo de Mill vide DIAS, 2012, p. 495. 
capacidade de agir por hábito que permite que o agente não calcule a todo instante sobre a melhor ação, mas antes possa agir conforme decisões passadas ou normas estabelecidas ao longo da história pelo princípio da utilidade. Todas as características presentes na natureza humana do indivíduo de Mill derivam seu valor da felicidade ou são requisitos para que os indivíduos a busquem.

Portanto, a característica central da natureza do indivíduo de Mill é a própria busca da felicidade ou, em outros termos, a maximização de prazer e minimização de dor, da qual deriva o valor de todas as outras características da natureza humana, quando se trata de ética ou moral. Os outros elementos da natureza humana (como a capacidade que o indivíduo tem de se transformar qualitativamente ao longo do tempo, a capacidade de agir por hábito e a capacidade de experimentar prazeres de qualidade superior) são ditos sub-teses da tese hedonista, pois extraem seu valor dela.

A capacidade que o indivíduo possui de se desenvolver qualitativamente ao longo do tempo está subordinada à tese hedonista, pois é pela experiência de prazeres, especialmente dos de qualidade superior, que esses indivíduos desenvolvem-se, modificam-se. A capacidade de agir por hábito também é uma subtese da tese hedonista, pois ela está intimamente relacionada ao benefício, vantagem, conveniência, ao útil, por possibilitar que os indivíduos poupem tempo ao agir e desenvolvam certa constância nas ações morais. A capacidade de experimentar prazeres de qualidade superior que o indivíduo possui relaciona-se totalmente à tese hedonista, de forma subordinada, pois apesar de diferenciar prazeres de qualidade superior e inferior, ainda é um elemento que diz respeito à busca dos prazeres.

Outra característica fundamental da natureza humana são as leis da mente (a. que toda impressão mental tem sua ideia e b. leis de associação³), por elas passam todas as leis empíricas para a for- 
mação de leis científicas, é através delas que se constroem todas as leis científicas das ciências sociais.

Tendo em vista este modelo de indivíduo, depreende-se que tal indivíduo certamente olha para si porque busca a sua felicidade, mas, ao mesmo tempo, não pode ser reduzido ao auto-interesse, pois conforme os arranjos sociais evoluem, conforme as faculdades elevadas são despertadas, compreende que a busca da felicidade é algo que, muitas vezes, constitui em nela não pensar, em obter muitos e variados prazeres, em possuir tranquilidade e emoção, em transformar em seu próprio interesse os interesses dos outros (Mill, 2000, p. 196-7, 202), não constituindo, portanto, uma vida de arroubos ou uma vida egoísta.

A felicidade de que falavam não significava uma vida de arroubo, mas momentos de êxtase numa existência constituída de poucas dores transitórias, muitos e variados prazeres, com um claro predomínio do ativo sobre o passivo [...]. A deplorável educação, os deploráveis arranjos sociais são, atualmente, o único obstáculo real a que quase todos a realizem [...] “Os principais elementos constitutivos da vida satisfeita parecem ser dois [...]: tranquilidade e emoção [...]. Depois do egoísmo, a principal causa que torna a vida insatisfatória é a falta de cultivo intelectual [...] (Ibid., p. 196-7).

Para que fosse formada a natureza do indivíduo moral de Mill, foram extraídas leis empíricas (verificações da experiência humana) sobre o comportamento humano, sendo estas, por indução, transformadas em generalizações universais. Após serem transformadas em generalizações universais estas leis são aplicadas às leis do duas impressões foram frequentemente experimentadas (ou mesmo pensadas), simultaneamente ou em sucessão imediata, então, sempre que uma dessas impressões, ou a ideia correspondente, retorna, a ideia da outra tende a ser provocada. A terceira lei enuncia que a maior intensidade em uma ou nas duas impressões é equivalente, para torná-las a se provocar umas às outras, a uma maior frequência de conjunção. 
da mente e então deduzidas e verificadas novamente, comparadas à experiência, corroboradas ou rejeitadas e assim transformadas em leis científicas. Dessa forma, é possível compreender as leis gerais da natureza humana, bem como a principal dentre elas (porque é dela que as outras leis retiram seu valor), a saber: o fato de que os indivíduos sentem prazer e dor e buscam a felicidade.

Este é o fundamento das ações humanas e é também a finalidade da moral: "se a felicidade for absolutamente impossível para todos os seres humanos, sua realização não pode constituir a finalidade da moral [...]" (Ibid., p. 195).

Está claro, portanto, que a moral tem por finalidade garantir a felicidade dos seres humanos, entretanto, qual é a definição de moralidade para Mill, no que ela se constitui? Mill a define da seguinte forma:

Assim, é possível definir a moralidade como as regras e os preceitos de conduta humana, cuja observação permitiria que uma existência tal como a descrita fosse assegurada, na maior medida possível, a todos os homens (Ibid., p. 194-5)4.

Portanto, conforme é tese deste trabalho, o utilitarismo de Mill apresenta um amplo espaço para a elaboração de regras morais, para além do princípio de utilidade, precisamente porque a sociedade descrita por Mill é composta de indivíduos com uma natureza complexa ${ }^{5}$ que não se reduz à tese hedonista. Dessa natureza deriva seu princípio de utilidade também complexo (ainda

4 E Mill continua dizendo que esta existência feliz deveria ser assegurada a todos os seres sencientes de criação. "e não apenas a eles, mas também, na medida em que comporte a natureza das coisas, a todos os seres sencientes da criação".

5 Toda vez que nos referirmos a uma natureza complexa do indivíduo de Mill pode-se entender que a natureza desse indivíduo não se reduz à tese hedonista (que os homens buscam o prazer e fogem da dor), mas possui outros elementos (como a capacidade que o indivíduo tem de se transformar ao longo do tempo qualitativamente, a capacidade de agir por hábito e a capacidade de experimentar prazeres de qualidade superior através das faculdades elevadas). 
com a tese hedonista fundamental), mas com espaço para muitos outros elementos que precisam ser entendidos para a busca da felicidade, finalidade da moralidade (Ibid., p. 187). Dentre eles, encontra-se na própria definição de moral do utilitarismo de Mill o fato de que preceitos e regras de conduta humana são necessários para a observação de uma vida feliz.

Conforme mencionado, aqueles que não levam uma vida egoísta (fonte de uma vida infeliz) alcançam objetos de afeto pessoal e também afetos públicos, fazendo convergir seus interesses com os coletivos.

Por outro lado, os que deixam atrás de si objetos de afeto pessoal e, sobretudo, os que também cultivam a solidariedade com os interesses coletivos da humanidade conservam, na beira da morte, um interesse pela vida tão intenso como o que mantinham no vigor da juventude e da saúde. Depois do egoísmo, a principal causa que torna a vida insatisfatória é a falta de cultivo intelectual (Ibid., p. 197).

Um espírito cultivado, de acordo com Mill, encontra recursos de interesse inesgotável em tudo o que o rodeia. Mill, contudo, não se refere ao espírito de um filósofo, mas ao de qualquer indivíduo que descobriu as fontes de conhecimento e que aprendeu a exercer suas faculdades elevadas. Tal indivíduo encontra prazer nos objetos da natureza, nas obras de arte, nas criações da poesia, nos incidentes da história, nos caminhos da humanidade e em suas perspectivas para o futuro. Portanto, a aceitação da tese hedonista (de que os indivíduos buscam o prazer e fogem da dor) no utilitarismo de Mill não implica que os homens sejam egoístas ${ }^{6}$, pois os seres humanos, por possuírem a capacidade de experimen-

6 "Menos ainda existe uma necessidade inata de que todo homem deva ser um egoísta arraigado” (MILL, J. S. Utilitarismo (1861). Trad. Eunice Ostrensky. São Paulo: Martins Fontes, 2000, p. 198.). 
tar prazeres de qualidade superior7 e por poderem se desenvolver ao longo do tempo de maneira qualitativa, ficam suscetíveis a se interessarem por questões públicas, afetos públicos e, muitas vezes, acabam por incluir em seus interesses os interesses dos outros como uma obrigação (Ibid., p. 219), algo que seria contrário ao egoísmo.

Todo ser humano criado corretamente mostra que, em graus distintos, são possíveis afetos privados genuínos e um interesse sincero no bem público (Ibid., p. 198).

Para que os homens possam ter uma vida feliz, um dos elementos importantes a serem considerados refere-se à formação de seu caráter. Para a boa formação do caráter dos indivíduos (da etologia individual), da etologia política ou do caráter nacional seria necessário uma forte melhoria nos arranjos institucionais, propiciando educação e a prudência dos desejos dos homens. De acordo com Mill, a felicidade que os utilitaristas adotaram como padrão do que é certo não é a felicidade do próprio agente, mas a felicidade de todos os envolvidos, pois o que conta na soma de felicidade conjunta é o prazer total ${ }^{8}$.

Está claro que o agente deve buscar sua própria felicidade e pode, principalmente, por sanção interna ${ }^{9}$ fazer convergir seus interesses com os interesses comuns, conforme os arranjos institucionais aperfeiçoam-se. Agir dessa forma é louvável, mas não

7 É importante notar que às faculdades elevadas estão associados prazeres qualitativamente superiores não intercambiáveis por prazeres de qualidade inferior, embora as necessidades básicas de um indivíduo devam ser satisfeitas para que as faculdades elevadas possam ser apreciadas devidamente. [Gibbs, 1986, p. 45]

8 " [...] a felicidade que os utilitaristas adotaram como padrão do que é certo na conduta não é a do próprio agente, mas a de todos os envolvidos" (Mill, 2000, p. 202).

9 A desaprovação interna é um sentimento de dor que um indivíduo sente por não cumprir seu dever, em outras palavras é um sentimento de dor que o indivíduo sente por gerar dor aos outros. A desaprovação externa ou constrangimento externo também existe e significa desaprovação por membros da comunidade em relação aos atos de indivíduos que geram dor no cômputo geral do balanço entre prazer e dor. 
obriga o indivíduo a sempre ter que incluir em seus interesses os interesses dos outros (Ibid., p. 252). Muito menos a moralidade utilitarista recomenda que um agente se obrigue a abrir mão de sua felicidade pessoal, em nome da felicidade dos outros.

Honra aos que podem negar a si mesmos o gozo pessoal da vida, quando por tal renúncia contribuem dignamente para aumentar o montante de felicidade no mundo! Mas quem realiza esse sacrifício ou professa realizá-lo para outro propósito não merece mais a admiração do que o asceta instalado em sua coluna. Ele pode ser uma prova animadora do que os homens podem fazer, mas certamente não é um exemplo do que deveriam fazer (Ibid., p. 201).

Voltando à questão sobre o que possibilita a formação do caráter nacional (etologia nacional e individual), sabe-se que é a elaboração de arranjos institucionais adequados (que coloca os indivíduos em adequadas circunstâncias para poderem experimentar prazeres de qualidade superior), bem como a prudência dos desejos, que tornam possível formar agentes com um caráter capaz de fazer coincidir seus interesses com os interesses da comunidade. Apresenta-se abaixo, uma passagem do Utilitarismo que corrobora a forte conexão entre o desenvolvimento do caráter com a melhoria dos arranjos institucionais.

Num mundo em que há tantas coisas interessantes, tantas coisas agradáveis, e tanto para se corrigir e melhorar, cada um que possuir essa quantidade moderada de requisitos morais e intelectuais será capaz de levar uma existência invejável, por assim dizer; e, a menos que tal pessoa seja negada por meio de más leis ou pela sujeição à vontade de outros, a liberdade para usar as fontes da felicidade a seu alcance, não deixará de encontrar essa existência invejável se conseguir escapar aos males absolutos da vida - grandes fontes de sofrimento físico e mental, tais como a indigência, a doença e a perda rude, indigna ou prematura dos objetos do afeto. A principal ênfase do problema reside, portanto, na luta contra es- 
sas calamidades [...] frustrações relacionadas a circunstâncias mundanas se devem, sobretudo, quer à grave imprudência de desejos desregrados, quer a instituições sociais más ou imperfeitas (Mill, 2000, p. 199).

Dessa forma, para fazer coincidir os interesses individuais com os coletivos e assim maximizar a felicidade de todos os agentes envolvidos em uma ação o ideal de utilidade recomenda os seguintes meios: a) que as leis e os dispositivos sociais deveriam colocar (através do estímulo da livre vontade) o interesse de cada indivíduo em harmonia com o interesse do todo (Mill, 2000, p. 203), b) que a educação e a opinião as quais são tão poderosas sobre o caráter humano deveriam ser direcionadas para estabelecer, no espírito de cada indivíduo, uma associação indissolúvel entre sua própria felicidade e o bem do todo. Mais uma vez as leis da mente entram em questão. É a lei de associação que pode fazer associar a felicidade individual com a felicidade coletiva em um indivíduo. O autor tem argumentado em diversos livros, como a Autobiografia (Id., 2007, p. 69) ${ }^{\mathrm{e}} \mathrm{o}$ Utilitarismo (Id., p. 218), que motivos de ação, como a simpatia entre indivíduos, são ingredientes indispensáveis à constituição de uma sociedade coesa.

Assim, verifica-se que Mill descreve ditames para melhor moldar o caráter dos indivíduos, como melhores arranjos institucionais para fazer convergir muitos dos interesses individuais com os coletivos, bem como indica a melhoria da educação como uma saída para o refinamento dos gostos dos indivíduos, através da ativação das faculdades elevadas.

Os adversários do utilitarismo criticam esse modelo por ser demasiado elevado para a humanidade. Segundo afirmam, a pretensão de que as pessoas sempre ajam de acordo com o desejo de promover os interesses gerais da sociedade é uma exigência demasiado alta. Entretanto, isto é compreender mal o significado mesmo de um padrão de moralidade, e confundir a regra como motivo da ação. É assunto da ética informar a todos quais são os 
deveres dos agentes, nenhum sistema de ética exige, porém, que o único motivo de todas as ações seja o sentimento de agir para gerar o benefício alheio (Ibid., p. 204). Ao contrário, a maioria das ações dos indivíduos é praticada por outros motivos e é corretamente praticada se a regra do dever não a condena.

[...] não há nada na teoria utilitarista incoerente com o fato de que outras coisas nos interessam nas pessoas além da justiça ou injustiça de suas ações (Ibid., p. 206).

Mill, ao efetuar a defesa do utilitarismo, ressalta que não há nada na teoria utilitarista incoerente com o fato de que outras coisas interessam às pessoas além da justiça ou injustiça de suas ações. Os utilitaristas estão perfeitamente cientes de que existem, além da justiça ou injustiça das ações para com outros, outros bens e outras qualidades desejáveis e estão inteiramente dispostos a atribuir a todos eles seu pleno valor.

Tendo em vista que a justiça e a injustiça das ações não constituem as únicas preocupações dos indivíduos, há também espaço para indicações para uma boa vida na moralidade do utilitarismo de Mill, conforme se tem mostrado (Ibid., p. 206). Tudo isto compõe a arte da moralidade e satisfaz a natureza complexa do indivíduo, descrita por ele. Há que se lembrar, contudo, que na origem destas regras morais estão os ditames da busca do prazer e fuga da dor, ainda que o hábito, qualidade, também, da natureza humana, possibilite o descolamento da busca pelo prazer no momento das ações, conforme confirma passagem abaixo:

A vontade, fenômeno ativo, é diferente do desejo, estado de sensibilidade passiva; e embora em sua origem seja um rebento do desejo, pode com o tempo deitar raízes e se desapegar da cepa materna, tanto é assim que, no caso de um propósito buscado por hábito, em vez de querer uma coisa porque a desejamos, com frequência a desejamos apenas porque a queremos" [...]. Às vezes isso é feito de maneira inconsciente, já que 
a consciência vem só depois da ação; outras vezes se trata de um ato de vontade consciente, mas de uma vontade que se tornou habitual e se põe em ação pela força do hábito [...] (Ibid., p. 240).

No que diz respeito à moralidade, Mill verifica que os homens, na prática, adquirem crenças firmes e nelas se baseiam quanto ao efeito de algumas ações sobre a felicidade. Estas são as chamadas regras da moralidade costumeira, são preceitos (como não roube, não mate, deseje desenvolver o intelecto, leia, aprecie a arte, seja corajoso, etc.) que constituem as regras da ética para os homens comuns, bem como para o filósofo, até que, com o tempo, conforme a sociedade progrida ${ }^{10}$, consigam-se outras regras morais secundárias ${ }^{11}$ que maximizem ainda mais o prazer dos indivíduos.

[...] e as crenças assim transmitidas constituem as regras da moralidade para multidão, bem como para o filósofo, até que consiga encontrar outras melhores [...]. [...] Os corolários do princípio de utilidade, assim como os preceitos de todas as artes práticas, são suscetíveis de um avanço indefinido [...] (Ibid., p. 212).

Poder-se-ia indagar se este indivíduo não efetua um cálculo a cada ação para revisar os costumes ou a moralidade costumeira, aplicando o princípio da utilidade no que diz respeito à tese hedonista. A reposta é negativa. Pelo fato do indivíduo de Mill ser dotado de uma natureza complexa que não se resume à tese hedonista e inclui, por exemplo, a capacidade de agir por hábito, é possível que tal indivíduo aja sem efetuar um balanço entre prazer e dor

10 A palavra progresso é usada, por Mill, como sucessão de estados sociais e individuais que podem ser para melhor ou pior (maximizando felicidade ou não). Contudo, o autor tende a pensar que, em geral, o progresso maximiza o prazer.

11 É importante notar que princípios secundários podem ser suplantados por outros, por determinação do princípio da utilidade. 
a cada ação. O indivíduo do utilitarismo de Mill, por possuir esta natureza complexa ${ }^{12}$, pode determinar uma moralidade com mais espaço para a elaboração de regras. O próprio hábito, como componente da natureza humana, permite que os indivíduos ajam conforme regras ou normas decididas no passado que se transformaram na moralidade costumeira. É importante notar que a moralidade costumeira também passou pelo crivo do princípio de utilidade no passado e pode ser alterada de acordo com ele, caso entre em conflito com outra regra costumeira (Hoag, 1983, p. 51).

No fundamento da moralidade está a felicidade como finalidade. Em outras palavras, a tese central do princípio de utilidade de Mill é a aprovação de qualquer ação na medida em tenda a maximizar felicidade ou minimizar dor, contudo pelo fato do indivíduo de Mill possuir uma natureza humana complexa, seu princípio de utilidade derivado da noção de natureza humana também torna-se complexo. A complexidade do princípio de utilidade de Mill reside no fato deste autor ter aventado em sua formulação mais elementos do que somente a tese hedonista. $\mathrm{Na}$ própria definição do princípio de utilidade consta o fato de que para dar uma ideia clara do padrão de moralidade estabelecido pela teoria, muito mais precisaria ser dito, além do fato de que o prazer é desejável e a dor é objeto de repúdio. Abaixo cita-se a formulação do princípio de utilidade de Mill, o famoso parágrafo 2.2 do Utilitarismo de Mill:

O credo que aceita a utilidade ou o princípio da maior felicidade como fundação da moral sustenta que as ações são corretas na medida em que tendem a promover a felicidade e erradas conforme tendam a produzir o

12 A natureza humana complexa do indivíduo de Mill além da tese hedonista apresenta elementos como o agir por hábito, faculdades elevadas que se satisfazem com prazeres de qualidade superior, a capacidade de se transformar ao longo do tempo e ainda possui as leis mentais que permitem formular novas leis científicas sociais. 
contrário da felicidade. Por felicidade se entende prazer e a ausência de dor, por infelicidade, dor e a privação do prazer. Para dar uma clara ideia do padrão moral estabelecido pela teoria, é preciso dizer muito mais; trata-se de saber, em particular, o que está incluído nas ideias de dor e prazer e em que medida esse debate é uma questão aberta. Mas essas explicações suplementares não afetam a teoria de vida sobre a qual se funda a teoria da moralidade, a saber, que o prazer e a imunidade à dor são as únicas coisas desejáveis como fins, e que todas as coisas desejáveis (as quais são tão numerosas no esquema utilitarista como em qualquer outro) são desejáveis quer pelo prazer inerente a elas mesmas, quer como meios $^{13}$ para alcançar o prazer e evitar a dor (Mill, 2000, p. 187).

Conforme citado, o princípio de utilidade de Mill pode incluir explicações adicionais a respeito do padrão moral estabelecido, embora isto não afete o fato do autor continuar a ser um utilitarista ou, em outros termos, o autor persiste sustentando que é correto que as pessoas persigam a felicidade e errôneo que as pessoas persigam a dor. Este princípio de utilidade complexo, ou preceito complexo, sustentado nesta tese, advém da natureza humana complexa do indivíduo de Mill. Uma pergunta, então, poderia ser colocada: como as outras características do indivíduo de Mill articulam-se para derivar outros preceitos morais que não apenas o princípio de utilidade? A tese hedonista, característica fundamental da natureza do indivíduo de Mill, dá origem ao tema central do princípio de utilidade que ressalta que os indivíduos devem buscar prazer e devem fugir da dor. O fato dos indivíduos serem dotados de faculdades elevadas, quando ativadas, permite que os indivíduos possam experimentar prazeres de qualidade superior, prazeres propriamente humanos. Além disso,

13 Em outros parágrafos Mill ressalta que os indivíduos podem desejar outros fins que não a felicidade e estes fins seriam como que partes da felicidade e não meioS. Há também o argumento de que os indivíduos poderiam agir inconscientemente e, portanto, estarem visando algum fim sem estarem pensando momentaneamente na felicidade. Vide Mill, 2000, p. 234. 
uma vez que os indivíduos experimentam tais prazeres eles não os trocam por prazeres inferiores ${ }^{14}$, pois os homens não trocam vidas propriamente humanas por vidas de outros animais. Esta característica permite que os indivíduos tomem gosto por apreciar o desenvolvimento intelectual, pela arte, pelo desenvolvimento de simpatia pelos outros, pelo desenvolvimento de sentimentos morais (gostar de praticar o bem ou gerar prazer a outros), por fazer convergir seus interesses com os da sociedade, etc. Normas do costume acabam por surgir dessas preferências. Do agir por hábito surge a possibilidade do agente não precisar efetuar um balanço entre prazer e dor a cada ação. Devido a essa característica da natureza humana, torna-se possível que o indivíduo possa agir de acordo com regras morais que foram frutos de cálculos ou acordos passados ${ }^{15}$ Em outras palavras, o agente pode agir de acordo com regras da moralidade costumeira (como não mate, não roube, desenvolva-se intelectualmente, aprecie a arte, seja corajoso, etc.), sem precisar se remeter a todo instante ao primeiro princípio. Da capacidade do indivíduo de se transformar ao longo do tempo surge sua característica dinâmica, emerge a possibilidade do agente poder se desenvolver, principalmente, intelectualmente, conforme o tempo passa. Essa característica também é derivada das faculdades elevadas, pois o indivíduo desenvolve-se ao longo do tempo de forma qualitativa ${ }^{16}$.

Todos os elementos da ciência da natureza humana do indivíduo de Mill convertem-se em preceitos ou contribuem para a formulação de preceitos. O preceito primeiro e fundamento da

14 Isto é claro considerando que suas necessidades básicas foram atendidas.

15 É importante notar que as regras da moralidade costumeira, em algum momento da história da humanidade, foram fixadas pela maximização de prazer que demonstraram ter quando aplicadaS. Assim, quando, em alguma circunstância, essas regras entram em conflito ou passam a demonstrar que não mais maximizam prazer, então podem ser substituídas, à luz do princípio de utilidade.

16 Vide Dias, 2012, p. 497: "As diferenças entre os conceitos de moral no utilitarismo de Bentham e John Stuart Mill: A moralidade derivada das respectivas noções de natureza humana". 
teoria da utilidade é o princípio da utilidade, mas esse princípio, apesar de ter como tema central a tese hedonista, abre espaço para que mais elementos sejam aventados para que as noções de prazer e dor sejam melhor compreendidas. Com essa abertura do princípio de utilidade, princípios secundários da moral podem ser formulados como derivados das sub-teses da tese hedonista (como o agir por hábito, a capacidade que cada um tem de se desenvolver ao longo do tempo qualitativamente e a possibilidade da experiência de prazeres de qualidade superior). O hábito contribui para a formulação de regras da moralidade costumeira, na medida em que permite que os indivíduos possam agir segundo cálculos de prazer e dor passados. O hábito permite a constância das ações morais, pois os indivíduos, devido a esse elemento, podem agir sem raciocinar (calcular). A capacidade que os indivíduos possuem de se desenvolver ao longo do tempo permite que eles escolham regras costumeiras, conforme essas regras ativem suas faculdades elevadas e forneçam-lhes prazeres superiores.

Assim, por todos esses elementos adicionais da natureza do indivíduo de Mill torna-se possível que regras costumeiras ou princípios secundários sejam formulados, como nos exemplos: não roube, não mate, seja corajoso, não minta, que um indivíduo se desenvolva intelectualmente, que aprecie a arte, que simpatize com os outros, que se interesse pelos assuntos públicos, que faça convergir seus interesses com os dos outros, entre outras normas morais que podem ser convertidas das características científicas da natureza humana do indivíduo de Mill. Dessa forma, tem-se a possibilidade da formação de uma moral com a efetuação de regras morais que não serão questionadas a cada ação, mas de tempos em tempos, conforme o indivíduo progrida. Vale lembrar que nenhuma das regras morais do indivíduo de Mill viola a tese hedonista ou o princípio de utilidade de busca da felicidade por parte do agente, uma vez que todas visam ao fim último coletivo e individual que é a busca da felicidade. 
Os corolários da ética, os princípios secundários ou preceitos da moralidade parecem ter mais força compulsória do que o teorema original. Entretanto, deve-se ter em mente que estes princípios secundários de ação ou regras da moral foram formados, porque na origem de uma determinada ação o indivíduo considerava mais prazeroso do que doloroso efetuá-la. Porém, uma vez que determinada ação torna-se habitual, os agentes não mais pensam nas ações que efetuam quando agem. Eles agem de acordo com os princípios secundários da moral.

Corroborando o que foi dito, afirma Mill:

Pois a moralidade gerada pelo costume, a que se consagram a educação e a opinião, é a única que se apresenta ao espírito com o sentimento de ser em si mesma obrigatória (Mill, 2000, p. 217).

As regras morais dividem-se entre: 1) as que dizem respeito à condução da vida de uma pessoa ou direitos e deveres de obrigação imperfeita (como que o intelecto seja aprimorado, que a arte seja apreciada, que o bem ao próximo seja feito, etc.) e 2) as mais obrigatórias que se relacionam a questões de justiça e, portanto, geram direitos e deveres ${ }^{17}$ de obrigação perfeita. O dever é algo que pode ser exigido de uma pessoa, tal como o pagamento de uma dívida (Ibid., p. 252). Portanto, as regras morais que podem ser designadas como obrigações morais não se distinguem das regras de justiça, pois geram direitos e deveres. As regras morais que geram direitos e que, portanto, estão associadas às condições essenciais do bem-estar humano, em outras palavras, as regras morais que são mais rigorosamente obrigatórias do que outras regras de conduta da vida são as regras que proíbem os

17 "Além disso o sentimento de justiça compreende dois elementos essenciais, a saber: o desejo de punir a pessoa que causa o dano e o conhecimento ou a crença de que há um ou mais indivíduos determinados a quem foi causado o dano (derivados do impulso de autodefesa e do desejo de simpatia)" (MILL, 2000, p. 256). 
seres humanos de causar prejuízo a outros. Tais regras morais aplicam-se quando ocorre uma interferência injusta na liberdade dos indivíduos.

Para que tais regras sejam relacionadas à questão da liberdade faz-se necessária a compreensão das duas máximas essenciais de ação ou princípios secundários de liberdade da ação ancorados no princípio de utilidade, a saber:

o indivíduo não é responsável perante a sociedade por suas ações, enquanto estas não afetarem os interesses de nenhum outro além dele mesmo. Conselhos, instrução, persuasão e isolamento, caso julguem necessário recorrer a este último meio para seu próprio bem, são as únicas medidas pelas quais a sociedade pode com justiça exprimir seu desagrado (Ibid., p. 143).

Esta máxima demonstra que regras morais ou preceitos podem ser gerados quando não há interações entre indivíduos, como que se aprecie a arte, que se aprimore o intelecto, entre outras. Ademais, é possível que haja uma certa sanção moral (como o isolamento, instrução ou conselho) no que tange a indivíduos que não cumprem estas regras, contudo, não são regras morais que geram direitos e deveres de obrigação perfeita, como o segundo tipo de regras. As regras morais que geram direitos dizem respeito à segunda máxima da liberdade, conforme será asseverado.

As regras morais que podem ser designadas como obrigações morais (o segundo tipo de regras acima descrito) não se distinguem da justiça, pois geram direitos e deveres. As regras morais que geram direitos e deveres e, portanto, estão associadas às condições essenciais do bem-estar humano são as regras mais rigorosamente obrigatórias do que outras regras de conduta da vida. São as regras que pró́bem os seres humanos de prejudicarem uns aos outros. Essas regras estão de acordo com a segunda máxima da liberdade, citada a seguir: "o indivíduo é responsável pelas ações 
prejudiciais aos interesses de outros, sujeitando-se então quer à punição social, quer à legal, se a sociedade julgar que uma ou outra seja necessária à sua proteção" (Ibid., p. 144).

Logo, regras morais, como por exemplo: que não se deve privar alguém de sua liberdade, não quebrar expectativas (ou quebrar contratos), não roubar, não matar, entre outras, podem, inclusive, se transformar em normas legais. Aquilo que decidirá se a norma será legal ou moral, quando diz respeito à segunda máxima da liberdade será, em última instância, um cálculo entre custo e benefício ou um apelo ao primeiro princípio.

Ficaríamos gratos por ver a conduta justa imposta e a injustiça reprimida, até os mais ínfimos detalhes, se, com razão, não receássemos confiar aos magistrados um poder tão ilimitado sobre os indivíduos. Quando pensamos que uma pessoa está, com justiça, obrigada a praticar um ato, dizemos, em linguagem corrente, que ela devia ser compelida a praticá-lo. Seria agradável a nós ver a obrigação imposta por alguém que tivesse poder para isso. Se vemos que essa compulsão exercida pela lei seria inconveniente, lamentamos a impossibilidade, consideramos como um mal a impunidade conferida à injustiça, e nos empenhamos em reparar esse mal, conferindo uma expressão enérgica a nossa desaprovação do público que será infligida ao culpado. Assim, é sempre a ideia de um constrangimento legal que está na origem da noção de justiça, ainda que esta sofra diversas transformações até tomar a forma acabada que apresenta num estado avançado da sociedade (Ibid., p. 152).

Ademais ressalta-se que não há diferença de natureza entre as regras morais (que geram direitos) e as regras legais ou regras de justiça, segundo enuncia Mill: "nada nos permite distinguir a obrigação de justiça da obrigação moral em geral” (Mill, 2000, p. 203), pois é o princípio da utilidade que explicará a permanência de uma regra de conduta no âmbito moral ou legal, considerando o mal que o indivíduo pode causar e a possível perda de liberdade, pois menos liberdade gera mais dor para o agente e mais liber- 
dade gera mais prazer para o indivíduo em questão. Isto porque entende-se que, ao criar regras legais, o governo tem o poder de tolher a liberdade dos indivíduos. Contudo, pode assim fazê-lo quando o cálculo entre prazer e dor apontar para mais prazer do que dor para a sociedade ao restringir a liberdade de alguém que ocasiona dor (mal).

Assim, todas as regras morais que geram direitos constituem deveres a serem cumpridos por aqueles que geraram um direito e estas regras são todas relacionadas à segunda máxima da liberdade que enuncia que um indivíduo é responsável perante a sociedade por gerar mal a outrem, caso viole o dever que deve cumprir. Regras morais desse tipo são as seguintes: aquele que empenha a sua palavra não deve mentir (essa é a regra moral), pois de acordo com a segunda máxima da liberdade, uma vez dada a palavra, mentir ocasiona um mal a um terceiro que tem o direito a receber a verdade. Além disso, as pessoas têm o direito a sua liberdade (conforme enunciou-se acima), a liberdade representa um direito dos homens e é um dever que seja garantida ${ }^{18}$, então cria-se a regra legal de que o Estado deve garantir a segurança dos indivíduos e pode restringir a liberdade de determinados agentes caso sua liberdade ocasione mais dor do que prazer à sociedade. Outras regras morais que geram direitos a indivíduos dizem respeito a tratar alguém conforme o mérito e não privar ninguém do que lhe pertence (este também é o tipo de regra que deve ficar sob a jurisdição do Estado, pois só ele pode garantir os pertences de alguém). A imparcialidade, especialmente, em um julgamento, é um bom exemplo de regra moral que gera um direito moral, pois seu rompimento gera dor, dano. Manter expectativas geradas é outra regra moral que gera direito, pois seu rompimento também ocasiona dor, mas sem

$18 \mathrm{O}$ Estado deve garantir a manutenção da liberdade dos indivíduos, pois só este tem o poder coercitivo suficiente para mantê-la. 
dúvida deve ser mantida, apenas sob o escopo da moralidade, podendo obter repressão informal social, uma vez que formular uma lei formal para que as pessoas cumpram as expectativas geradas (Mill, 2000, p. 271) ocasionaria uma demasiada intromissão na liberdade dos indivíduos.

É importante notar que regras da moralidade costumeira, ou princípios secundários da moral, são fundamentadas no princípio de utilidade ou no teorema original e passaram a ser aceitas, ao longo da história da humanidade, devido à concordância com o princípio da utilidade ou, em outros termos, por gerarem mais prazer do que dor. Assim, caso esses princípios secundários da moral entrem em conflito entre si em uma determinada circunstância ou entrem em conflito com alguma circunstância prática, o princípio da utilidade sempre pode ser chamado para decidir, à luz de um cálculo entre prazer e dor, se o princípio secundário deve ser violado.

As outras regras morais que podem gerar o bem entre indivíduos (regras de beneficência) e as regras que não envolvem interações entre indivíduos, são regras que o indivíduo segue para melhor conduzir sua vida rumo à felicidade. São regras morais que não geram um dever (West, 2007, p. 118) ou um direito, mas também são necessárias, pois sempre há bons motivos para que se faça o bem, seja pela força do hábito, seja por um apelo ao primeiro princípio (para que se aumente o somatório do prazer no cômputo geral dos prazeres) e há excelentes razões para que os agentes coloquem regras morais para sua conduta de vida rumo à felicidade, embora as regras obrigatórias (Skorupski, 2007, p. 36) (que geram direitos morais) versem sobre ações que podem ocasionar mal entre indivíduos. Conforme ressalta Mill:

o interesse que tem em inculcar em cada um o dever de beneficência positiva é incontestável, mas num grau muito menor, pois é possível que não necessitemos dos benefícios de outros. Mas sempre necessitamos que não nos causem prejuízo. Assim, as regras morais que protegem cada 
indivíduo dos prejuízos que os outros possam causar-lhe, seja impedindo sua liberdade de procurar o seu próprio bem, são as que lhe são mais caras. [...] Ora, são essas regras morais que fundamentam a obrigações de justiça (Mill, 2000, p. 270).

Não obstante, as outras regras que não geram direitos e deveres, mas também são derivadas da natureza humana complexa do indivíduo de Mill, como fazer convergir o interesse próprio com o interesse coletivo, cultivar a arte, o intelecto e obter prazeres de qualidade superior (regras totalmente relacionadas ao fato do indivíduo possuir faculdades elevadas) são também parte da moralidade e totalmente importantes à busca da felicidade. $\mathrm{Na}$ passagem seguinte Mill afirma que a moralidade é maior do que os casos de justiça que geram uma obrigação moral (que são os casos que são passíveis de gerar dor aos outros):

Onde quer que haja um direito, há um caso de justiça e não de beneficência; e quem não situar a distinção entre justiça e moralidade em geral onde acabamos de situar acabará por não fazer distinção alguma entre elas e reduzirá toda a moralidade à justiça (Ibid., p. 255).

Portanto, independente do fato das regras da moralidade do indivíduo de Mill serem divididas em regras morais que geram direitos e, portanto, pertencerem às regras de justiça, ou constituírem regras da moralidade que não geram direitos morais e, portanto, apenas apontarem como o indivíduo melhor se conduz no mundo seja individualmente, seja coletivamente fazendo o bem (gerando prazer), o que é importante ter em vista é que o indivíduo de Mill se coloca no campo prático dotado dos princípios secundários devido à natureza complexa que possui.

Em outras palavras, há uma moral positiva ${ }^{19}$ para Mill, mais 
ampla do que apenas a constituição do primeiro princípio, com regras estabelecidas por decisões passadas (moralidade dos costumes) embasadas em um cálculo (no primeiro princípio) e possibilitada pela natureza complexa de seu indivíduo (composta pelas leis da mente, tese hedonista, capacidade de agir por hábito, faculdades elevadas e capacidade de se transformar ao longo do tempo qualitativamente). Conforme argumentou-se, tais regras não são contestadas por um cálculo entre prazer e dor, a cada ação, mas, principalmente de tempos em tempos, segundo o progresso social. Alguém poderia indagar se este indivíduo não seria menos livre pelo fato de elaborar mais regras morais. A resposta é negativa, pois Mill identifica a falta de liberdade com a interferência nas liberdades individuais, principalmente por parte do governo. Este só deve intervir, nos casos em que há a iminência de geração de mal por indivíduos uns aos outros, especialmente no caso da segurança (como nos casos de risco de se retirar a liberdade de alguém, a propriedade e em alguns outros casos especiais). O indivíduo não é responsável perante a sociedade no que diz respeito às outras regras morais que não geram direitos, conforme enuncia a primeira máxima de liberdade. O máximo que a sociedade pode fazer no que diz respeito a estas regras é dar conselhos, instruir, isolar o indivíduo, mas não cobrá-lo como se cobra o pagamento de uma dívida. Além disso, a elaboração de regras morais não significa a diminuição da liberdade dos indivíduos, uma vez que esses indivíduos necessitam de regras no campo prático do agir para melhor atingir a felicidade. A questão toda reside na maneira como este indivíduo irá agir, se através de um cálculo a todo instante que parece não ser a opção do indivíduo de Mill ou através do hábito e outros elementos da natureza humana que permitem a formulação de mais regras morais, para que melhor se alcance a felicidade. 


\section{Conclusão}

Conforme demonstrou-se ao longo deste artigo, da natureza humana complexa do indivíduo de Mill, composta de elementos adicionais à tese hedonista, como a capacidade de agir por hábito, a presença de faculdades elevadas passíveis de serem ativadas por meio da experiência de prazeres de qualidade superior, a capacidade que o indivíduo tem de se modificar qualitativamente e a presença das leis da mente, deriva um número de regras morais adicionais ao princípio de utilidade. Embora esses princípios secundários possam ser alterados à luz do princípio da utilidade, com o passar do tempo, em geral, eles são mais facilmente reconhecidos (inclusive pelos sentimentos), do que o primeiro princípio.

Além disso, foi explanado que os princípios secundários podem ser divididos em regras que não geram direitos e deveres de obrigação perfeita (como regras que dizem respeito à condução da vida) e regras morais ou legais que geram direitos e deveres de obrigação perfeita. Essas últimas referem-se, especialmente, às ações que geram dor.

As regras morais que não geram direitos e deveres de obrigação perfeita relacionam-se à primeira máxima da liberdade que elenca que um indivíduo não é responsável perante a sociedade no que diz respeito às ações que não envolvem interações. As regras morais que geram direitos e deveres de obrigação perfeita referem-se à segunda máxima da liberdade que ressalta que os indivíduos são sujeitos à punição social, moral ou legal, quando geram dor aos outros.

Contudo, independente do conjunto ao qual as regras morais pertencem e de sua relação com as máximas da liberdade restou claro que a moralidade, para Mill, não se resume apenas ao princípio de utilidade; ao contrário, ela abrange inúmeras outras regras derivadas da natureza complexa do indivíduo de Mill. 


\section{Bibliografia}

BENTHAM, J. An Introduction to the Principles of Moral and Legislation. Edinburgh, William Tait, 1843.

Uma Introdução aos Princípios da Moral e da Legislação. São Paulo, Abril Cultural, 1973.

BURNE P. "Bentham and The Utilitarian Principle”. Mind, New Series, V. 58, n. 231,1949 .

CRISP, R. Routledge Philosophy Guidebook to Mill on Utilitarianism. London and New York, Routledge, 1997.

DIAS, M. C. L. C. "As diferenças entre os conceitos de moral no utilitarismo de Bentham e John Stuart Mill: A moralidade derivada das respectivas noções de natureza humana”. Princípios, v. 19, $\mathrm{n}^{\circ}$ 32, 2012.

DONNER, W. The Liberal Self. New York, Cornell University Press, 1991.

FEAGIAN, L. S. Mill and Edwards on the Higher Pleasures. Philosophy. V. 58, n. 224,1983 .

GIBBS, B. Higher and Lower Pleasures. Philosophy. v. 61, n. 235, 1986.

GOLDWORTH, A. Bentham's Concept of Pleasure: Its Relation to Fictitious Terms. Ethics, v. 82, n. 4, 1972.

HEAN, S. J. Was Mill a Moral Scientist? Cambridge, Cambridge University Press. v.67, n. 259, 1992.

HOAG, R. W. Mill on Conflicting Moral Obligations. Analysis. Oxford, Oxford University Press, v. 43, n. 1, 1983.

LYONS, D. Mill's theory of morality. Nous 10, 1976.

MCCLOSKEY, H. J. John Stuart Mill: A Critical Study. Londres, Macmillan, 1971.

MILGRAM, E. Mill's Proof of the Principle of Utility, Ethics, v. 110, 2000.

MILL, J. S. A Lógica das Ciências Morais. São Paulo, Iluminuras, 1999 $(1843)$.

A System of Logic. Edited by John M. Robson. Toronto: University of Toronto Press, 1985 (1843).

Autobiografia. Editado por Alexandre Braga Massella. São Paulo, Iluminuras, 2007 (1873).

Autobiography. Edited by John M. Robson. Toronto, University of Toronto Press, 1985 (1873). 
MILL, J. S. Bentham. Edited by John M. Robson. Toronto, University of Toronto Press, 1985 (1838).

Liberdade. Trad. Eunice Ostrensky. São Paulo, Martins Fontes, 2000 (1859).

Utilitarismo. Trad. Eunice Ostrensky. São Paulo, Martins Fontes, 2000 (1861).

Utilitarianism. Edited by John M. Robson. Toronto, Toronto University Press, 1985 (1861).

Utilitarianism and On Liberty. Ed.by Mary Warnock, Oxford, Oxford University Press, 2003 (1861).

Utilitarianism. Edited by Roger Crisp. New York, Oxford University Press, 1998 (1861).

RILEY, J. Mill's Qualitative Hedonism. The Philosophical Quartely, v. 53, n. 212, 2003 .

ROBSON, M. J. The Improvement of Mankind: the Social and Political Thought of John Stuart Mill. Toronto, University of Toronto Press, 1968.

RYAN, A. The Philosophy of John Stuart Mill. Londres, Routledge, 1974. SKORUPSKI, J. John Stuart Mill. Londres e Nova York, Routledge, 1989. .Why Read Mill Today? Londres e Nova York, Routledge, 2006.

WEST, H. Mill's Utilitarianism. Londres, Continuum, 2007. 